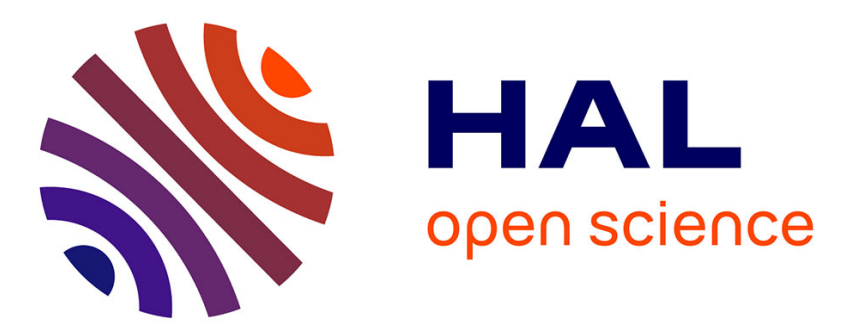

\title{
Magnetic structure of Basse-Terre volcanic island (Guadeloupe, Lesser Antilles) inferred from 3D inversion of aeromagnetic data
}

Anne Barnoud, Claire Bouligand, Olivier Coutant, Julie Carlut

\section{To cite this version:}

Anne Barnoud, Claire Bouligand, Olivier Coutant, Julie Carlut. Magnetic structure of Basse-Terre volcanic island (Guadeloupe, Lesser Antilles) inferred from 3D inversion of aeromagnetic data. Journal of Volcanology and Geothermal Research, 2017, 10.1016/j.jvolgeores.2017.10.005 . hal-01628482

\section{HAL Id: hal-01628482 \\ https://hal.science/hal-01628482}

Submitted on 3 Nov 2017

HAL is a multi-disciplinary open access archive for the deposit and dissemination of scientific research documents, whether they are published or not. The documents may come from teaching and research institutions in France or abroad, or from public or private research centers.
L'archive ouverte pluridisciplinaire HAL, est destinée au dépôt et à la diffusion de documents scientifiques de niveau recherche, publiés ou non, émanant des établissements d'enseignement et de recherche français ou étrangers, des laboratoires publics ou privés. 


\section{Accepted Manuscript}

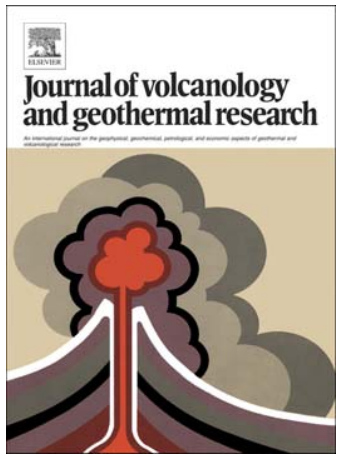

Magnetic structure of Basse-Terre volcanic island (Guadeloupe, Lesser Antilles) inferred from 3D inversion of aeromagnetic data

Anne Barnoud, Claire Bouligand, Olivier Coutant, Julie Carlut

PII: $\quad$ S0377-0273(17)30343-8

DOI: $\quad$ doi: $10.1016 /$ j.jvolgeores.2017.10.005

Reference: $\quad$ VOLGEO 6213

To appear in: Journal of Volcanology and Geothermal Research

Received date: 2 June 2017

Revised date: $\quad 3$ October 2017

Accepted date: 10 October 2017

Please cite this article as: Barnoud, Anne, Bouligand, Claire, Coutant, Olivier, Carlut, Julie, Magnetic structure of Basse-Terre volcanic island (Guadeloupe, Lesser Antilles) inferred from 3D inversion of aeromagnetic data, Journal of Volcanology and Geothermal Research (2017), doi:10.1016/j.jvolgeores.2017.10.005

This is a PDF file of an unedited manuscript that has been accepted for publication. As a service to our customers we are providing this early version of the manuscript. The manuscript will undergo copyediting, typesetting, and review of the resulting proof before it is published in its final form. Please note that during the production process errors may be discovered which could affect the content, and all legal disclaimers that apply to the journal pertain. 


\title{
Magnetic structure of Basse-Terre volcanic island (Guadeloupe, Lesser Antilles) inferred from 3D inversion of aeromagnetic data
}

\author{
Anne Barnoud $^{\mathrm{a}, \mathrm{b}, *}$, Claire Bouligand ${ }^{\mathrm{a}}$, Olivier Coutant ${ }^{\mathrm{a}}$, Julie Carlut $^{\mathrm{c}}$ \\ ${ }^{a}$ Univ. Grenoble Alpes, Univ. Savoie Mont Blanc, CNRS, IRD, IFSTTAR, ISTerre, \\ F-38000 Grenoble, France \\ ${ }^{b}$ Now at Université Clermont Auvergne, CNRS/IN2P3, LPC, F-63000 Clermont-Ferrand, \\ France \\ ${ }^{c}$ Institut de Physique du Globe de Paris, Université Paris Diderot, Sorbonne Paris-Cité, \\ UMR 7154, CNRS, 1 rue Jussieu, 75238 Paris Cedex 05, France
}

\begin{abstract}
We interpret aeromagnetic data to constrain the magnetic structure of the island of Basse-Terre, Guadeloupe, Lesser Antilles. Aeromagnetic data are inverted in the spatial domain with a Bayesian formulation to retrieve the $3 \mathrm{D}$ distribution of rock magnetization intensity and polarity. The inversion is regularized using a correlation length and standard deviation for magnetization chosen to be consistent with results from paleomagnetic measurements on lava flow samples from Basse-Terre. The resulting 3D model of magnetization is consistent at the surface with observed polarities and at depth with a 2D model obtained from a Parker and Huestis (1974) inversion in the Fourier domain. The inferred magnetic structure is compared with the available geological information deduced from published geological, geomorphological and geochronological studies. In the southern part of the island, very low magnetization is observed around the Soufrière lava dome, last activity of the Grande-Découverte-CarmichaëlSoufrière composite volcano, in relation with a high level of hydrothermal alteration. High-magnetizations in the South-East might reflect the presence of massive lava flows and lava domes from the Madeleine vents and Monts Caraïbes.
\end{abstract}

\footnotetext{
*Corresponding author

Email address: anne.barnoud@gmail.com (Anne Barnoud)
} 
Medium magnetizations in the South-West coincide with the location of debris avalanche deposits associated with the collapse of the former Carmichaël volcano and might reflect less massive lava structure at depth. Using the volume of normal polarity in the South part of Basse-Terre recovered in our 3D model of rock magnetization, we estimate an average construction rate of $\sim 9.4 \times 10^{-4} \mathrm{~km}^{3} / \mathrm{yr}$ during the Brunhes chron which provides new insights on the volcanic activity of La Soufrière volcano.

Keywords: magnetism, inversion, volcanology

2010 MSC: 00-01, 99-00

\section{Introduction}

Basse-Terre is the main volcanic island of the Guadeloupe archipelago. It is located in the central part of the Lesser Antilles arc resulting from the subduction of the Atlantic oceanic lithosphere beneath the Caribbean plate. The volcanic history of the island is now well established thanks to paleomagnetic, geological, geochronological and geomorphological studies (Boudon et al., 1989; Carlut et al., 2000; Carlut and Quidelleur, 2000; Feuillet et al., 2002; Samper et al., 2007, 2009; Lahitte et al., 2012; Mathieu et al., 2013; Ricci et al., 2015a). A southward migration of volcanism is observed across geological times, forming, in chronological order (fig. 1; ages from Blanc, 1983; Carlut et al., 2000; Feuillet et al., 2002; Samper et al., 2007, 2009; Lahitte et al., 2012) : the Basal Complex (2.79-2.68 Myr), the Septentrional Chain (1.81-1.15 Myr), the Axial Chain, Sans-Toucher and Bouillante Chain (1.02-0.435 Myr), the Monts Caraïbes (555-472 kyr), the Icaques-Capesterre and Vieux-Habitants volcanics (600-200 kyr), the Madeleine vents and Trois Rivière Complex (150-11 kyr) and the Grande-Découverte-Carmichaël-Soufrière Complex (200 kyr-present) that hosts the recent Soufrière lava dome. Since the last magmatic eruption of this volcano around 1530 A.D. (Boudon et al., 2008), intense hydrothermal activity is observed over the Soufrière lava dome but also in the Bouillante thermal area located on the eastern coast of Basse-Terre island (e.g., Komorowski et al., 2005). 
The volcanic complexes of Basse-Terre are mainly composed of lava flows, lava domes and pyroclastic deposits of mainly andesitic to basaltic-andesitic composition and rare more acidic products. Recent studies have attempted to provide 3D reconstructions of the island at various stages of its history (Samper et al., 2007, 2009; Lahitte et al., 2012; Ricci et al., 2015a). These studies show that the island of Basse-Terre underwent various episodes of extrusion of magmatic material and destruction through erosion and flank collapse (Boudon et al., 2007). In addition, these studies provide estimates of volumes or rates of construction and destruction, which are key quantities for hazards assessment in a volcanic area.

Geophysical studies at the scale of Basse-Terre island provide constrains on its subsurface structure. Dorel et al. (1979) built layered models of compressional velocity along East-West profiles across the island. Compilations of gravimetric measurements (Coron et al., 1975; Barthes et al., 1984; Gunawan, 2005; Matthieu et al., 2011; Barnoud et al., 2016) were used to construct 2D layered models (Gailler et al., 2013) and 3D models (Barnoud et al., 2016) of rock density. 2D layered models of rock magnetization were also constructed by Gailler et al. (2013) using an aeromagnetic survey flown over Guadeloupe (Le Mouël et al., 1979). These various models identify dense anomalies at depth that may correspond to cooled magmatic intrusions possibly associated with former volcanic feeding systems. On the other hand, shallow low density and low magnetization are observed in areas characterized by high level of hydrothermal alteration such as around the Soufrière lava dome or the Bouillante thermal area. The models of rock magnetization also indicate a possible distribution of magnetic polarities recorded in the subsurface. Knowing the location of polarity reversals at depth may be of particular interest to reconstruct the evolution of a volcanic island. Indeed, polarity reversal provides a chronological constraint that could help to constrain construction rates of volcanic edifices.

Various methodologies can be used to construct models of rock magnetization that account for observed magnetic anomalies. Because the interpretation of potential field methods is non-unique, simplifying assumptions are necessary 
to reduce the level of ambiguity. Magnetic problems are even less constrained than gravity problems as the magnetic field is a vector that could potentially be oriented in various directions. However, the direction of the magnetic field is generally assumed constant and only the distribution of magnetization intensity and polarity is recovered. Many methods are based on the discretization of the volume into cells or nodes where magnetization is evaluated. The inversion of these models can be done in the spatial domain (e.g., Li and Oldenburg, 1996; Portniaguine and Zhdanov, 2002; Caratori Tontini et al., 2012) or in the spectral domain (e.g., Parker and Huestis, 1974). Other methods assume a fixed magnetization intensity of the source and search for its geometry, e.g. BlancoMontenegro et al. (2011) in the spatial domain and Pilkington and Crossley (1986) in the Fourier domain. These methods can provide 3D or 2D distributions of magnetization (assuming invariance in the third direction). The distribution of magnetization can also be investigated using forward modeling. In this case, an initial model is constructed based on independent geophysical and geological information and then progressively modified to better fit observed magnetic anomalies (e.g., Guillen et al., 2008). Magnetization can also be recovered using inversions with only little independent geophysical or geological data introduced through a regularization term.

In the context of a volcanic island, the anomalous magnetic signal is expected to be important as most of the volcanic rocks are fairly magnetic (eg. Telford et al., 1990; Dentith and Mudge, 2014) but its inversion is a difficult exercise because the distribution of magnetization is likely to vary in the three directions. Moreover, only very little a priori information is usually available on the distribution at depth to constrain the model, so that strong assumptions might be necessary to regularize the problem. For example, in order to image the subsurface of Tenerife (Canary Islands), Blanco-Montenegro et al. (2011) made successive simplifying assumptions to reduce the number of unknown parameters. They first performed a linear inversion of the distribution of magnetization intensity using a layer of prisms beneath topography to investigate the lateral variations of magnetization. They second performed a non-linear inversion of 
the geometry of the magnetic sources characterized by a constant magnetization intensity to image deep intrusive body. On the other hand, Okuma et al. (2014) performed a fully 3D regularized inversion of the distribution of magnetization intensity in the Usu Volcano in Japan. On Basse-Terre volcanic island, only 2D layered magnetization models from Gailler et al. (2013) are available. These models were constructed using forward modeling starting with initial models based on the seismic layers defined by Dorel et al. (1979).

In this paper, we perform a linear inversion of aeromagnetic data available for Basse-Terre to provide a 3D model of the distribution of the magnetization intensity and polarity, assuming remanent magnetization is dominant. As we have few information on the actual distribution of magnetization at depth, this inversion is performed using a Bayesian formalism with an a priori model defined using a Gaussian correlation function to impose a smooth magnetization model (e.g. Tarantola, 2005), following the same framework as detailed by Barnoud et al. (2016) for the inversion of gravimetric data. Existing paleomagnetic and geochronological data from rock samples (Blanc, 1983; Carlut et al., 2000; Carlut and Quidelleur, 2000; Samper et al., 2007, 2009; Ricci et al., 2015a,b, 2017, and Julia Ricci, pers. com.) provide us with the polarity and intensity of rock natural remanent magnetization at a few locations at the surface of the island (fig. 1). These data are used to guide our choice of the regularizing $a$ priori model. The purpose of this study is to improve our understanding of the subsurface structure of the island. We are particularly interested in the location of normal and reverse polarities at depth to provide age constraints and delineate various stages of the island construction.

In the following, we first detail the data from Basse-Terre island that we use, including the aeromagnetic data and the information from geochronological and paleomagnetic measurements on rock samples. We then explain the Bayesian linear inversion method that we implement and we apply it to the data from Basse-Terre island. Lastly, we discuss our results in terms of structure and age of the subsurface of the island. 


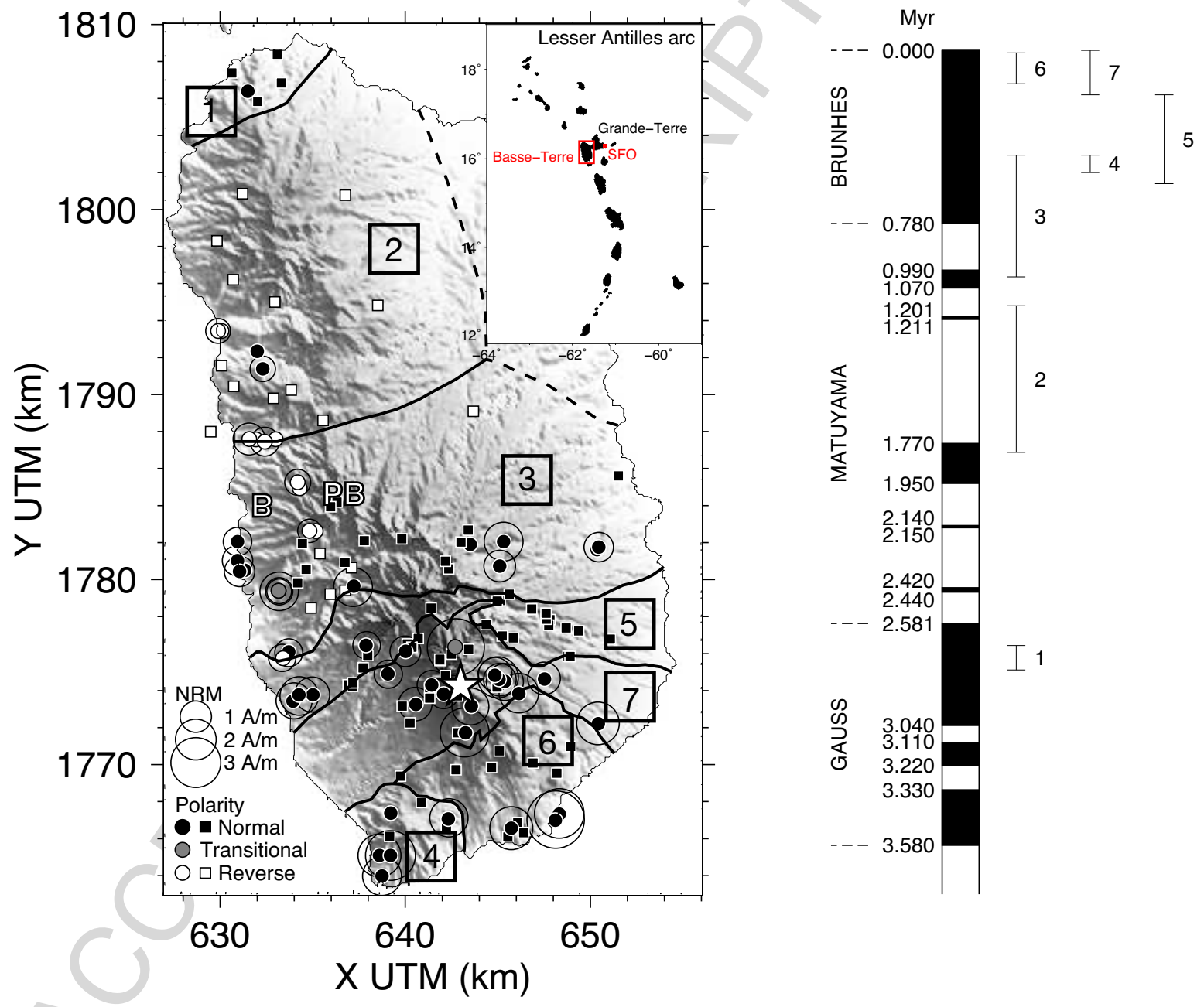

Figure 1: Left: Map of Basse-Terre island with location of natural remanent magnetization (NRM) intensity and polarity measurements (from Blanc, 1983; Carlut et al., 2000; Carlut and Quidelleur, 2000; Samper et al., 2007, 2009; Ricci et al., 2015a,b, 2017, and Julia Ricci, pers. com.). The polarities were inferred either from paleomagnetic direction measurements (circles) or from K-Ar age measurements (squares). Note that NRM intensity is not available for all sites. White star: La Soufrière lava dome. The top right inset shows the location of BasseTerre island in the Lesser Antilles Arc. Right: Geomagnetic time scale (Cande and Kent, 1995) and correspondence with successive volcanic edifices of Basse-Terre. By chronological order: $1=$ Basal Complex, $2=$ Septentrional Chain, $3=$ Axial Chain, Sans-Toucher and Bouillante Chain, $4=$ Monts Caraïbes, $5=$ Icaques-Capesterre and Vieux-Habitants volcanics, $6=$ Madeleine vents and Trois-Rivières Complex, $7=$ Grande-Découverte-Carmichaël-Soufrière Complex. Additional locations mentionned in the article: $\mathrm{SFO}=$ Saint-François Observatory, $\mathrm{B}=$ Bouillante, $\mathrm{PB}=$ Pitons de Bouillante. 6 


\section{Data}

\subsection{Aeromagnetic data}

We use here aeromagnetic data acquired over Basse-Terre island in 1975 at a constant altitude of $1800 \mathrm{~m}$ above sea level (Le Borgne and Le Mouël, 1976; Le Mouël et al., 1979). The acquisition and processing of the data is detailed in Le Borgne and Le Mouël (1976) and Le Mouël et al. (1979). We recall here the main information. These data consist of measurements of the magnetic field intensity performed using a proton magnetometer towed using a $100 \mathrm{~m}$ long cable. Data were acquired with a sampling rate of $1 \mathrm{~s}$ (corresponding to $\sim 70 \mathrm{~m}$ ) along East-West flight lines spaced $2.5 \mathrm{~km}$ apart and along a few North-South tie-lines leading to more than 14600 observations.

Positioning of data was obtained using visual navigation on land, resulting in uncertainties of $\sim 100 \mathrm{~m}$, and doppler navigation at sea, resulting in uncertainties of $\sim 1 \%$ of the distance from the coast (Le Borgne and Le Mouël, 1976). Elevation of data was estimated using both radar and barometric altimeters yielding uncertainties lower than $30 \mathrm{~m}$. Given orders of magnitude for vertical and horizontal gradients of the magnetic field intensity in the area, these location uncertainties result into a maximum error on the intensity of 8 nT(Le Borgne and Le Mouël, 1976).

Data were corrected for diurnal variations using measurements from the St François observatory on the Grande Terre island (Le Mouël et al., 1979, see observatory location on the top right inset of fig. 1). The authors performed a survey adjustment to minimize residuals at lines and tie lines intersections. From these residuals, they estimated the accuracy of measurements to $\sim 4-5 \mathrm{nT}$. Then, a North-South linear trend estimated from surveys over the Guadeloupe and Martinique islands was removed from the intensity data to compute magnetic anomalies (Le Mouël et al., 1979).

For this study, we have only access to anomaly data along the East-West lines. We keep the 8336 data located within the studied area. Location of flight lines and interpolated anomalies using a natural neighbor method with a 
grid spacing of $100 \mathrm{~m}$ are shown on fig. 2. As the flight line spacing is larger than the flight elevation above the ground, the interpolated map is likely to be much smoother than the real fluctuations of the magnetic field, especially in the NS direction perpendicular to flight lines. Also, the distance between magnetic data and topography varies across the island as the survey was flown at constant elevation above sea level. For this reason, larger anomaly amplitudes are observed along the NNW-SSE alignment of the highest peaks across the island. On the other hand, low-amplitude and long-wavelength anomalies are observed over the NE part of Basse-Terre which is characterized by a lower elevation (magnetic sources further from the survey elevation) and displays a volcano-sedimentary sequence (e.g., Komorowski et al., 2005, see NE part of fig. 1 limited by dash lines) that we expect to be less magnetic than massive lava flows. Moreover, magnetic anomalies display a sort of discontinuity along the topographic ridge suggesting observed magnetic anomalies are strongly influenced by topography. Note that, we do not correct the total-field magnetic anomalies for the topographic effect before the inversion because large variations of magnetization (including changes of polarity) are expected at the scale of the island. However, such topographic correction is not needed because the inversion takes topography into account. 


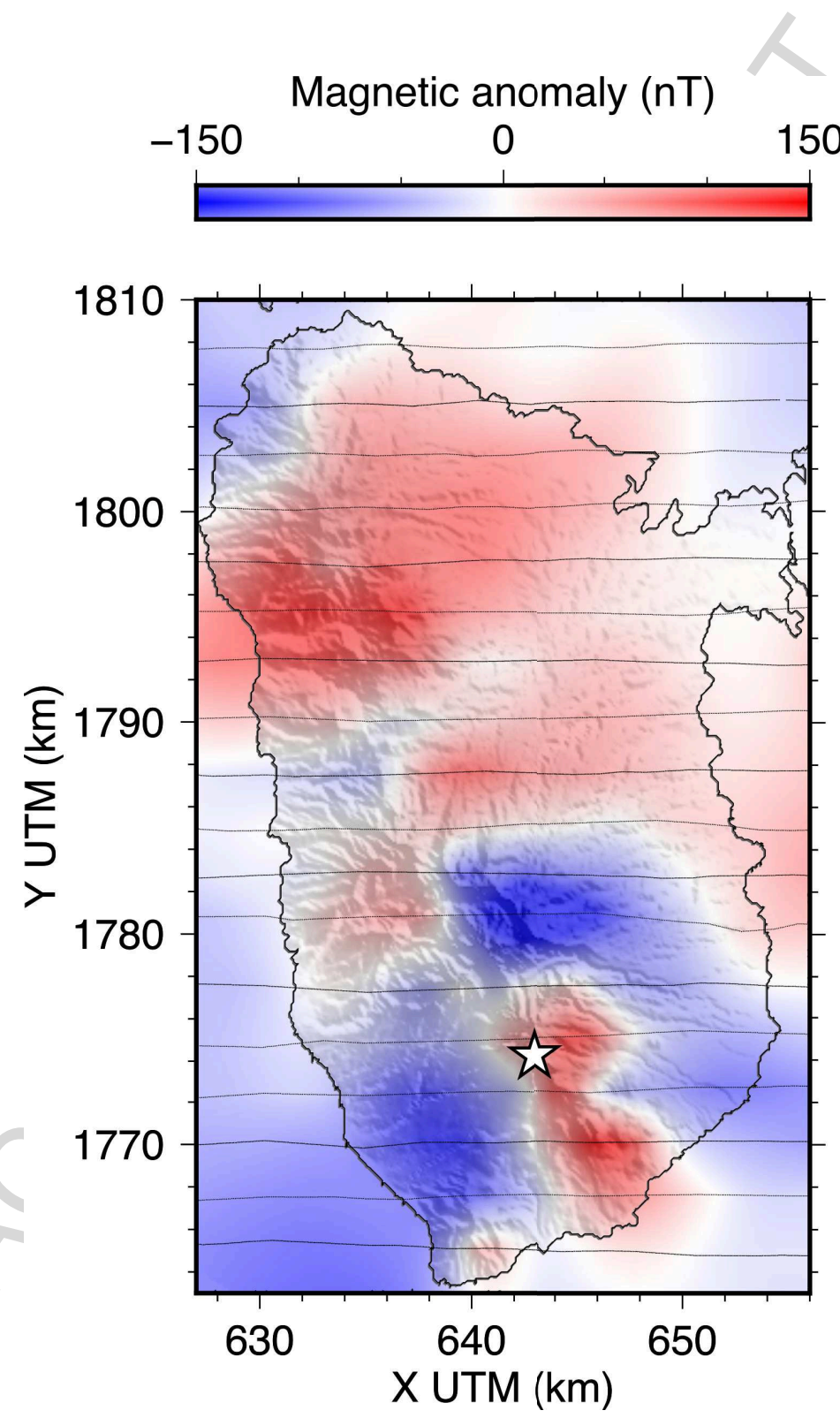

Figure 2: Interpolated aeromagnetic data from Le Borgne and Le Mouël (1976) andLe Mouël et al. (1979) superimposed on the shaded topography of Basse-Terre. Lines indicate the location of the original survey lines of Le Borgne and Le Mouël (1976); Le Mouël et al. (1979). Note that the Bayesian inversion was performed using the original flight line data and not the interpolated grid. White star: La Soufrière lava dome. 


\subsection{Magnetic properties of volcanic rocks}

In order to constrain the interpretation of aeromagnetic data, we also use paleomagnetic, geochronological and geothermal data to obtain a priori information on the distribution of magnetization direction and intensity in the subsurface. Since remanent magnetization is generally dominant over induced magnetization in volcanic rocks (Koënigsberger ratio larger than 1; e.g., Hunt et al., 1995), we neglect induced magnetization. Furthermore, because the rocks from Basse-Terre were formed during a period of time much larger than the characteristic time of secular variation ( 500 years $)$, we assume that the averaged direction of magnetization in the volcanic substratum is close to the direction of the magnetic field predicted by a Geocentric Axial Dipole (GAD), which is characterized at the latitude of Guadeloupe by a declination $D=0^{\circ}$ and an inclination $I \approx 30^{\circ}$. Such direction is indeed close to the averaged direction measured by Carlut et al. (2000) in lava flows from 27 sites in the South part of Basse-Terre $\left(D=0.0^{\circ}\right.$ and $\left.I \approx 29.6^{\circ}\right)$. Note that these directions correspond to characteristic remanent magnetizations obtained after removing paleomagnetic overprints and can therefore be different from natural remanent magnetization (NRM) directions. If the rock magnetization includes a certain amount of viscous overprint and/or induced magnetization, the magnetization direction might deviate from the GAD field direction and be shifted toward the regional magnetic field, which was $D \approx-11.5^{\circ}$ and $I \approx 45.5^{\circ}$ at $1800 \mathrm{~m}$ a.s.l. above the Soufrière volcano in 1975 during the acquisition of the aeromagnetic survey (as predicted by the International Geomagnetic Reference Field, IGRF; Thébault et al., 2015). The exact orientation of magnetization is therefore a source of uncertainty that could slightly alter the distribution of magnetization intensities and polarities in our model.

Geochronological and paleomagnetic measurements from Blanc (1983); Carlut et al. (2000); Samper et al. (2007, 2009); Ricci et al. (2015a,b, 2017) and Julia Ricci (pers. com.) provide the polarities of the geomagnetic field recorded in lava flows over the volcanic island. Known polarities are indicated on fig. 1 by circles when deduced from paleomagnetic direction measurements (Carlut et al., 
2000; Samper et al., 2007, and Julia Ricci, pers. com.) and by squares when deduced from K-Ar ages (Samper et al., 2007, 2009; Ricci et al., 2015a,b, 2017) and the geomagnetic time scale of Cande and Kent (1995). The geomagnetic time scale and the age of the successive volcanic edifices that form the island is also displayed on fig. 1. The most recent volcanic complexes in the South of Basse-Terre were formed during the current normal polarity event (Brunhes). Several polarity reversals occurred during the formation of the Axial Chain, Sans-Toucher and Bouillante Chain (labeled 3) and the Septentrional Chain (labeled 2). The Basal Complex emerged during a normal polarity interval.

In addition, intensity of natural remanent magnetization (NRM) of andesite lava flows were measured at 44 sites by Carlut et al. (2000) and Julia Ricci (pers. com.), in the South and West parts of Basse-Terre (see locations on fig. 1). Measurements performed on 2 to 5 paleomagnetic cores of $11 \mathrm{~cm}^{3}$ from each site are documented on fig. 3. The histogram of NRM on fig. 3 shows an asymmetrical distribution with values ranging from 0.1 to $4.9 \mathrm{~A} / \mathrm{m}$ (including $92 \%$ of values between 0.1 and $3 \mathrm{~A} / \mathrm{m}$ ) with a mean value of $1.5 \mathrm{~A} / \mathrm{m}$ and a standard deviation of $1.0 \mathrm{~A} / \mathrm{m}$. These estimates are in the same range of values than values measured by Bouligand et al. (2016) with samples from the Soufrière lava dome $(0.1$ to $3 \mathrm{~A} / \mathrm{m})$. Independent estimates of rock magnetization intensity were also obtained by Bouligand et al. (2016) using magnetic anomalies caused by topography observed on a ground magnetic survey over the Soufrière lava dome. They obtained magnetizations ranging from $\sim 0 \mathrm{~A} / \mathrm{m}$, on the flanks of the lava dome composed of randomly oriented altered boulders and debris, to $\sim 10 \mathrm{~A} / \mathrm{m}$, for massive rocks at the summit of the lava dome. This upper value is significantly larger than estimates from rock samples, but the study of Bouligand et al. (2016) concerned only a very small area at the top of La Soufrière lava dome where lightning induced magnetization as well as highly ferroan deposits are common. It is also expected that weathering and viscous components affect the older flows: indeed, the largest measured remanence values are mostly observed near the South coast of Basse-Terre in the Monts Caraïbes and in the Madeleine and Trois-Rivières Complex where the 
volcanism is younger (fig. 1). Therefore, we rather rely on the distribution of magnetization intensity deduced from samples displayed on fig. 3.

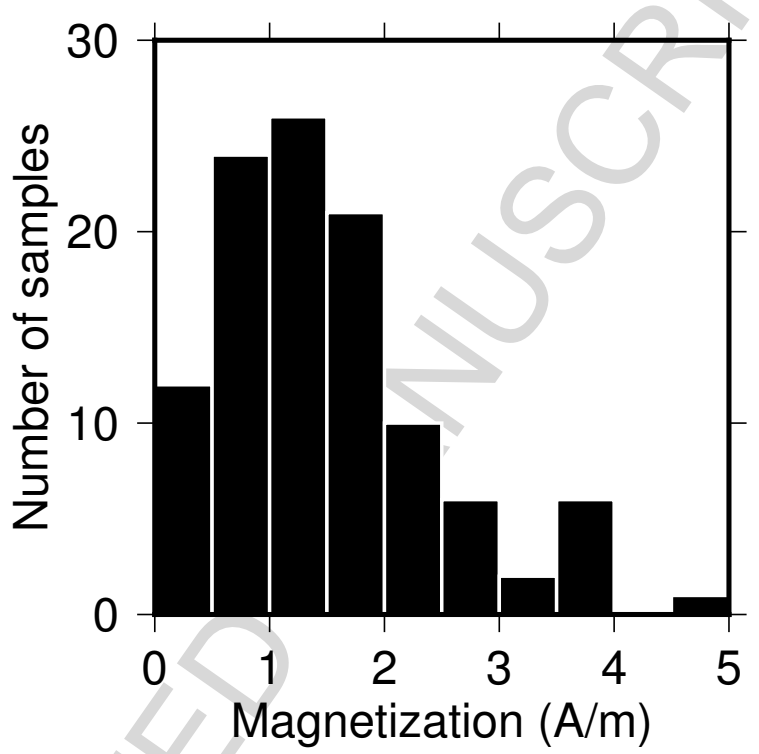

Figure 3: Histogram of natural remanent magnetizations (NRM intensities) measured on lava flow samples (from Carlut et al., 2000, and Julia Ricci, pers. com.). Samples are located on fig. 1.

Magnetic minerals lose their magnetization above their Curie temperature ( $\sim 580^{\circ} \mathrm{C}$ for magnetite, usually assumed to be representative of crustal magnetization; e.g., Hunt et al., 1995). An estimation of the depth to the Curie temperature isotherm would provide a lower bound of the model to invert. The depth to the bottom of magnetic sources can be estimated by analyzing the spectral content of magnetic anomalies (Spector and Grant, 1970; Maus et al., 1997; Bouligand et al., 2009; Bansal et al., 2011). However, estimating this depth at a single location requires the use of a very large map of aeromagnetic anomaly, about ten times larger than the depth to the Curie temperature isotherm (eg. Bouligand et al., 2009), so that only large wavelength spatial variations can be recovered. This approach would therefore not allow to recover the spatial variations of the depth to the Curie temperature isotherm at the scale 
of the island of Basse-Terre. Moreover these methods do not take into account magnetic anomalies due to topography, which are important in the case of a volcanic island. Nevertheless, Arnaiz-Rodríguez and Orihuela (2013) and Gailler et al. (2017) constructed maps of the depth to the bottom of magnetic sources for the Caribbean suggesting an averaged depth of $\sim 20 \mathrm{~km}$ for an area of a few $100 \mathrm{~km} \times 100 \mathrm{~km}$ around the Guadeloupe islands. The depth to the Curie temperature isotherm can also be estimated using heat flow measurements. A thermal flux of $\sim 101 \mathrm{~mW} / \mathrm{m}^{2}$ was estimated by Manga et al. (2012) from a drill hole in sediments in the Lesser Antilles Arc between Basse-Terre and the Montserrat island. Assuming a crustal thermal conductivity of $3 \mathrm{~W} /(\mathrm{m} \cdot \mathrm{K})$ and a steady state $1 \mathrm{D}$ conduction equation (i.e., a linear temperature vertical profile) or a half-space cooling model (Parsons and Sclater, 1977) yield in both cases to a depth to the Curie isotherm of $\sim 18 \mathrm{~km}$ (similar to the estimated depth to the bottom of magnetic sources mentioned above). The Curie temperature isotherm is, however, likely to be shallower beneath the volcanic island of Basse-Terre and especially below the Soufrière volcano where a magma chamber has been inferred at a depth of $\sim 6 \mathrm{~km}$ (eg. Hirn and Michel, 1979; Pozzi et al., 1979; Boichu et al., 2011; Allard et al., 2014). Indeed, Bouligand et al. (2016) suggested a depth to the Curie temperature isotherm of the order of $5 \mathrm{~km}$, assuming a temperature of $\sim 900^{\circ} \mathrm{C}$ for the magma chamber and a linear vertical temperature profile. A shallower Curie temperature isotherm is also suggested by the locally very high heat flows $\left(\sim 900-1000 \mathrm{~mW} / \mathrm{m}^{2}\right)$ measured by Feuillard (1976) in a shallow borehole near the Soufrière lava dome. However, these estimates cannot be used to estimate a depth to the Curie temperature isotherm as the borehole temperature profile shows clear evidences of fluid flow. These various estimates indicate that we do not expect the existence of magnetized material below a maximum depth that may vary in Basse-Terre island between $\sim 5 \mathrm{~km}$ (below the Soufrière volcano) and $\sim 20 \mathrm{~km}$. 


\section{Inversion method}

We describe below the inversion method used in this study: the forward model and the Bayesian inversion algorithm. This method is largely similar to the method detailed by Barnoud et al. (2016) for the inversion of gravity data. The method was adapted for the inversion of total-field magnetic anomaly data to obtain a 3D model of the magnetization intensity and sign (i.e., polarity), assuming constant directions for the geomagnetic field and for the rock magnetizations.

We use a 3D grid of nodes to describe the volume magnetization. For the forward modeling, the volume is divided into prisms whose magnetizations are constant, interpolated from the magnetizations assigned to the grid nodes. The topography is taken into account with a resolution that is consistent with the elevation of data acquisition above topography. The magnetic field produced by each prism is computed following Bhattacharyya (1964) and is proportional to its magnetization intensity. The vector magnetic anomaly at a given location is therefore linearly related to the grid nodes magnetization. The total-field magnetic anomaly $\Delta T$, which is defined as the difference between the intensities of the observed field and of a regional magnetic field can be obtained by projecting the magnetic anomaly vector $\boldsymbol{\Delta} \boldsymbol{F}$ along the direction of the regional field $\boldsymbol{F}$ (eg. given by an IGRF model such as Thébault et al., 2015):

$$
\Delta T \approx \frac{\boldsymbol{F} . \boldsymbol{\Delta} \boldsymbol{F}}{\|\boldsymbol{F}\|}
$$

This approximation is valid because the intensity of the crustal field is generally much smaller than the intensity of the regional field (e.g., Blakely, 1995). In doing so, we obtain a linear relationship between the total-field anomaly data contained in vector $\Delta \boldsymbol{T}$ and the rock magnetization intensity at grid nodes $\boldsymbol{M}$ :

$$
\mathbf{A} M=\Delta T
$$

where $\mathbf{A}$ is a linear operator. 
We use a Bayesian formulation to solve eq. 2 and minimize the following objective function containing a misfit and a regularization term (Tarantola and Valette, 1982; Tarantola, 2005):

$\phi(\boldsymbol{M})=(\boldsymbol{\Delta} \boldsymbol{T}-\mathbf{A} \boldsymbol{M})^{t} \mathbf{C}_{\boldsymbol{\Delta} \boldsymbol{T}}^{-1}(\boldsymbol{\Delta} \boldsymbol{T}-\mathbf{A} \boldsymbol{M})+\left(\boldsymbol{M}-\boldsymbol{M}_{\text {prior }}\right)^{t} \mathbf{C}_{\boldsymbol{M}}^{-1}\left(\boldsymbol{M}-\boldsymbol{M}_{\text {prior }}\right)$

where $\boldsymbol{M}_{\text {prior }}$ and $\mathbf{C}_{\boldsymbol{M}}$ are the expectation vector and covariance matrix defining the a priori model for magnetization intensities and $\mathbf{C}_{\boldsymbol{\Delta} \boldsymbol{T}}$ is the data error covariance matrix. $\mathbf{C}_{\boldsymbol{\Delta} \boldsymbol{T}}$ is a diagonal matrix with the variance of the magnetic anomaly, $\sigma_{T}{ }^{2}$. $\mathbf{C}_{\boldsymbol{M}}$ is a full matrix including the variance of the node magnetizations, $\sigma_{M}{ }^{2}$, and a Gaussian correlation function controlled by a spatial correlation length $\lambda, \mathbf{C}_{\boldsymbol{M}_{i j}}=\sigma_{M}{ }^{2} \exp \left(-\frac{d_{i j}{ }^{2}}{\lambda^{2}}\right)$, where $d_{i j}$ is the distance between nodes $i$ and $j$. This a priori model imposes a smooth solution to the problem. The derivation of the best estimator minimizing eq. 3 and its a posteriori covariance matrix are detailed in Tarantola (2005). The a posteriori covariance matrix allows us to compute the model resolution matrix (Tarantola, 2005) and associated resolution parameters. Following Backus and Gilbert (1968), we estimate spatial resolution length from the lines of the resolution matrix. Here, we choose to compute and display the horizontal resolution length that quantifies the width of the smallest recovered feature in the horizontal direction, as detailed in Barnoud et al. (2016).

The unique solution of eq. 3 is imposed by our choices of grid node discretization and a priori model. These choices need therefore to be carried out with caution and in consideration of the expected geologic structures to be imaged in the study area. However, the dimensions of the model and the number of parameters are also limited by computer memory requirements associated with the storage of matrices involved in the resolution of the problem.

Two main hypotheses are formulated when using this method. First we assumed that the direction of magnetization is constant and known beforehand. There are various geological contexts where this might not be the case, for example in areas where rocks with remanent magnetization have been affected by significant deformation and rotation. Second, the Bayesian formalism of 
Tarantola (2005) assumes that model parameters follow a unimodal normal distribution. In study areas including rocks formed during several polarity events like over Basse-Terre, we expect instead a bimodal distribution of magnetization intensities (with one lobe on the positive side and one lobe on the negative side). We assumed here that the standard deviation of magnetization intensity is large enough with respect to the averaged absolute intensity so that the bimodal distribution can be assimilated to a zero-mean unimodal distribution, in which case, the a priori expectation for magnetization $\boldsymbol{M}_{\text {prior }}$ is set to zero.

Our approach is relatively similar to the one from Li and Oldenburg (1996), although they used a different regularization term to impose smoothness of the solution and performed a non-linear iterative inversion algorithm. On the other hand, Portniaguine and Zhdanov (2002); Caratori Tontini et al. (2012) used different regularization terms to obtain a focused model with sharp contrasts of magnetization. Because of the non-uniqueness of the problem, other studies prefer to invert a 2D horizontal distribution of magnetization within a layer below topography. Such inversions are classicaly done in the Fourier domain (Parker and Huestis, 1974) but can also be performed in the spatial domain (Blanco-Montenegro et al., 2011; Honsho et al., 2012).

\section{Application to Basse-Terre}

\subsection{Assumptions and parameters}

The data vector that we invert is composed of 8336 total-field magnetic anomalies acquired above Basse-Terre island at an elevation of $1800 \mathrm{~m}$ above sea level (see fig. 2). Measurement errors are of the order of $\sigma_{T}=6 \mathrm{nT}$ (see section 2.1; Le Borgne and Le Mouël, 1976; Le Mouël et al., 1979).

The model that we invert covers the same area as the aeromagnetic data (see fig. 2) and extends at depth up to $4 \mathrm{~km}$ below the topographic surface. We stop the model below this depth because we expect 1 ) the bottom of magnetic sources to be close to $4 \mathrm{~km}$ below the Soufrière lava dome and 2) magnetic anomalies to be almost insensitive to spatial variations of magnetization at a depth larger 
than $4 \mathrm{~km}$ below topography (see sections 4.2 and 4.3 ). In this model, grid nodes are spaced $500 \mathrm{~m}$ apart in the three directions, so that it remains smaller than the flight line spacing of $2.5 \mathrm{~km}$. The topography is taken into account with a precision of $100 \mathrm{~m}$ which is smaller than the minimum distance of the data to the ground (350 $\mathrm{m}$ above the Soufrière lava dome), based on a Lidar digital elevation model (Litto3D data).

The magnetic field and the magnetization are assumed to have constant directions in the study area. The magnetic field direction predicted by the IGRF model (Thébault et al., 2015) at the time and location of the aeromagnetic survey is $\left(D \approx-11.5^{\circ}, I \approx 45.5^{\circ}\right)$. We assume that the rock magnetization is dominated by remanent magnetization and that it is characterized by a GAD field direction $\left(D=0^{\circ}, I \approx 30^{\circ}\right)$.

We set the a priori mean magnetization $\boldsymbol{M}_{\text {prior }}$ to zero, as the volcanic units of Basse-Terre have recorded both normal and reverse polarities (fig. 1). The spatial correlation length $\lambda$ is chosen based on the spatial distribution of normal and reverse polarities measured on rock samples (fig. 1) and the standard deviation of magnetization intensity $\sigma_{M}$ is chosen based on the histogram of magnetization (fig. 3). However, instead of fixing these parameters before the inversion, we performed several inversions and retained the combination $\left(\lambda, \sigma_{M}\right)$ that yields an a posteriori model with a histogram of magnetization intensities and a shallow distribution of polarities consistent with paleomagnetic measurements from lava flow samples (fig. 3 and 1). In doing so, we choose a standard deviation $\sigma_{M}$ of $1 \mathrm{~A} / \mathrm{m}$ (i.e., a ratio $\sigma_{M} / \sigma_{T}=1 / 6(\mathrm{~A} / \mathrm{m}) / \mathrm{nT}$ ) and a spatial correlation length $\lambda=8 \mathrm{~km}$. This corresponds to the lowest correlation length that allows the resulting model to be consistent with the distribution of rock sample polarities at the surface. Moreover, it is larger than the flight line spacing $(\sim 2.5 \mathrm{~km})$ and the grid spacing $(500 \mathrm{~m})$ and prevents therefore the existence of artifactual short-wavelength structures in the inverted model associated with the uneven distribution of data. 


\subsection{Results of the $3 D$ Bayesian inversion}

Cross-sections of the 3D model of magnetization intensity and polarities resulting from our 3D linear Bayesian inversion are shown on fig. 4a where red (resp. blue) indicates normal (resp. reverse) polarity. We observe that the distribution of magnetizations varies significantly with depth. The recovered structures are of relatively long wavelength as imposed by the correlation length of $8 \mathrm{~km}$. Magnetization intensities vary between 0 and $3 \mathrm{~A} / \mathrm{m}$. There are also obvious artefacts near the north and south edges of the study area where we observe strong intensities. These large values are probably due to edge effects and the absence of data beyond these edges (see fig. 2). The magnetic data computed from the resulting model show no visible differences with the aeromagnetic data except for a slight smoothing induced by the spatial correlation length of the model. The data RMS reaches $\sim 9.6 \mathrm{nT}$ for the scattered data that are inverted and $\sim 7.2 \mathrm{nT}$ when considering the interpolated maps.

Cross-sections of the lateral resolution associated with our model are represented on fig. 4b. This lateral resolution takes into account the geometry of the model discretization, the distribution of data, and the data errors and $a$ priori model covariances but is not influenced by the actual values of the magnetic anomaly data. As expected, lateral structures are better resolved (i.e., smaller resolution length) near the surface and especially in areas of high elevation which are close to the survey elevation. We also observe that the lateral resolution length increases faster with depth in areas of high topography (such as below the Soufrière lava dome) than in areas of low topography (such as below the axial chain). This might be due to the fact that superficial rocks in areas of high topography are very close to the survey elevation and dominate the magnetic anomaly signal (i.e., masking the signal associated with deeper sources). The comparison of fig. $4 \mathrm{a}$ and $4 \mathrm{~b}$ is useful to delineate artefacts that result from poor resolution. For instance, the obvious artefacts at the Northern and Southern edges of our study area correspond to a part of the model that is not resolved (very large resolution lengths of $\sim 20 \mathrm{~km}$ ). We also notice that the deep subsurface below a large portion of the South part of Basse-Terre 
encompassing the Grande-Découverte-Carmichaël-Soufrière complex is not well resolved. This suggests that the strong magnetization intensities displayed at this location on the cross-sections at depths 1 and $2 \mathrm{~km}$ on fig. $4 \mathrm{a}$ are not well constrained. On the other hand, we observe relatively low intensities at depth in the central and northern part of Basse-Terre where lateral resolution remains better than $\sim 15 \mathrm{~km}$ 
(a) Inversion result

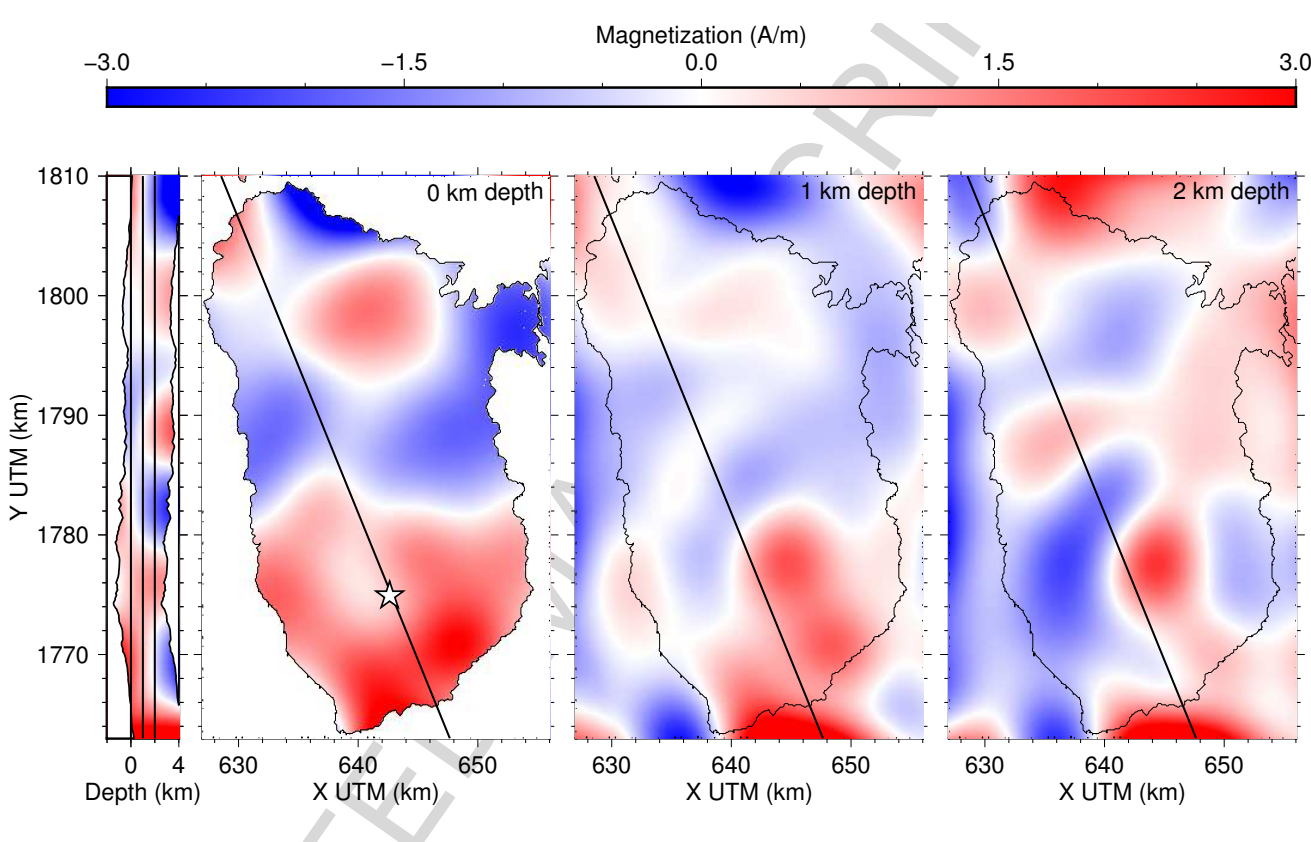

(b) Resolution

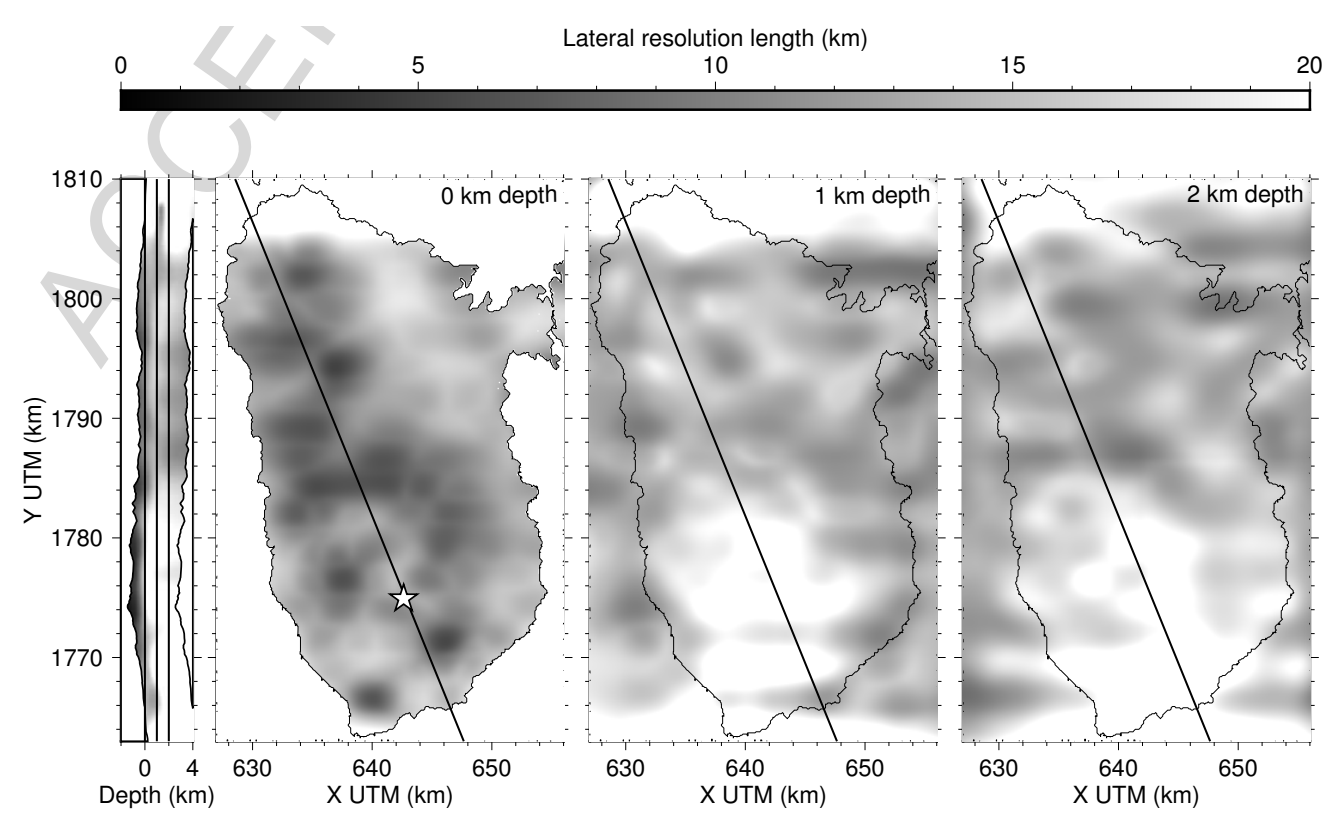

Figure 4: Vertical and horizontal sections extygcted from the 3D Bayesian inversion of aeromagnetic data. (a) Magnetization intensities and polarities. Absolute values give the intensities while the color indicates the polarity (red for normal polarity and blue for reverse polarity). (b) Lateral resolution length. Straight black lines on vertical and horizontal sections give the location of horizontal and vertical sections respectively. White star: La Soufrière lava dome. 


\subsection{Comparison with a $2 D$ inversion in the Fourier domain}

For comparison, we also use the Parker and Huestis (1974) method to estimate the lateral distribution of equivalent magnetization within a layer of constant thickness below topography. To this end, magnetic anomaly data are interpolated using a $100 \mathrm{~m}$ grid-spacing. The distribution of magnetization is obtained through an iterative algorithm in the Fourier domain and by applying a low-pass filter at each iteration to prevent the enhancement of short-wavelength noise. The layer thickness is set to $4 \mathrm{~km}$ as used for the Bayesian inversion. The low-pass filter cuts out signal with wavenumbers larger than $0.8 \mathrm{rad} / \mathrm{km}$ (i.e., wavelengths shorter than $\sim 8 \mathrm{~km}$ as used for the correlation length in our Bayesian inversion).

The resulting magnetization distribution (fig. 5b) displays similar patterns as the vertically averaged magnetizations of the 3D Bayesian inversion result (fig. 5c) but with amplitudes about twice lower. The data RMS associated with the Parker and Huestis (1974) model is $\sim 11.6 \mathrm{nT}$, larger than the $\sim 7.2 \mathrm{nT}$ for the interpolated data from our 3D Bayesian inversion. This data RMS is larger than data errors estimated by Le Borgne and Le Mouël (1976) and Le Mouël et al. (1979) but this is not surprising as this inversion is performed with a lowpass filter that prevents the inversion from reproducing the shorest wavelengths.

We also used the Parker and Huestis (1974) inversion to select the thickness of our Bayesian model. To this end, we performed various Parker and Huestis (1974) inversions with different layer thicknesses and looked at the evolution of the RMS of data residuals and of the RMS of differences between magnetization maps obtained for a given thickness and a half space (fig. 5b). We observe that data RMS decreases with the layer thickness but that this decrease becomes negligible for thicknesses larger than $4 \mathrm{~km}$. The RMS of magnetization with respect to a half-space model also decreases with the layer thickness and is equal to $\sim 0.15 \mathrm{~A} / \mathrm{m}$ for a $4 \mathrm{~km}$ thick layer, which corresponds to only $\sim 10 \%$ of the amplitude of the spatial variations of magnetization intensities shown on fig. 4a. We therefore concluded that rock magnetization below $4 \mathrm{~km}$ has a negligible contribution to observed magnetic anomalies. 
(a) Convergence with layer thickness
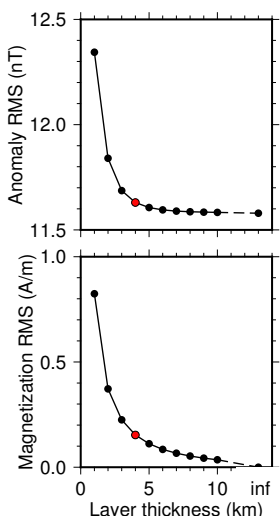

(b) Parker \& Huestis inversion result

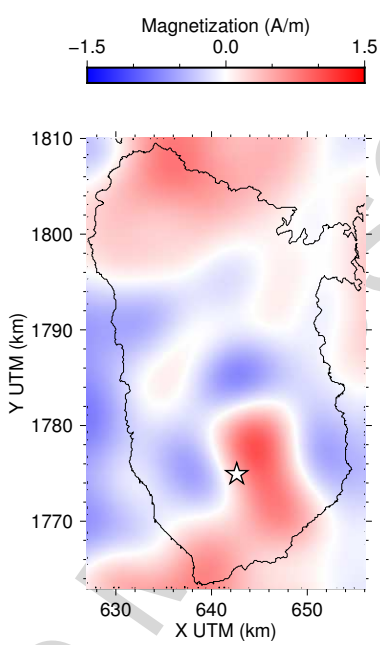

(c) Averaged Bayesian inversion result Magnetization (A/m) $\begin{array}{lllll}3.0 & -1.5 & 0.0 & 1.5 & 3.0\end{array}$

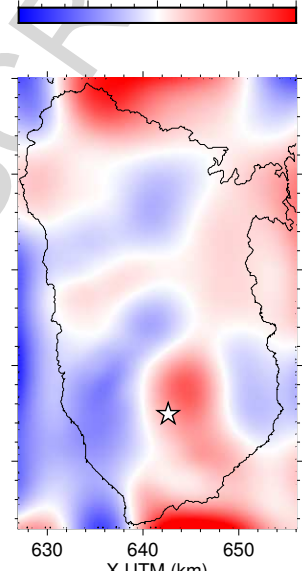

Figure 5: 2D inversion using the Parker \& Huestis (1974) method assuming that magnetization is constant in the vertical direction within a layer of given thickness and comparison with the Bayesian inversion result. (a) Convergence of the inversion result with the layer thickness. Top: RMS of data residuals. Bottom: RMS of differences between magnetization maps obtained for different layer thicknesses and magnetization map obtained for a half-space below topography. The red dot corresponds to the result displayed on panel (b). The last value "inf" refers to a layer of infinite thickness. (b) Result for a Parker \& Huestis (1974) inversion with a $4 \mathrm{~km}$ thick layer. (c) Vertically averaged magnetizations from the 3D Bayesian inversion result (fig. 4a). White star : La Soufrière lava dome.

\section{Discussion on the magnetic structure of Basse-Terre}

\subsection{Magnetization intensities}

The cross-sections of our 3D model on fig. 4a show strong spatial variations of magnetization intensities, with dark (resp. light) colors corresponding to large (resp. low) intensities. In the southern part of Basse-Terre, the distribution of magnetization intensities in the shallow subsurface can be compared with sample measurements (see fig. 6, center).

Very low magnetization intensities are observed around the Soufrière volcano 
both in our model and in sample measurements. This very low magnetization might result from high level of hydrothermal alteration in the volcanic substratum that transformed magnetic minerals into non-magnetic minerals (e.g., Komorowski et al., 2005; Salaün et al., 2011). This is consistent with the study of Gailler et al. (2013) who modeled the Soufrière volcano as a demagnetized structure. At a smaller scale, Bouligand et al. (2016) also evidenced the existence of a large volume of non-magnetic material within and below the Soufrière lava dome. In our model, the very low magnetization area also extends further to the North-West at depth (see section at $1 \mathrm{~km}$ depth in fig. 4a), in particular beneath the Grande-Découverte and Carmichaël former volcanic centers (e.g., Feuillet et al., 2002; Lahitte et al., 2012). These low magnetizations could possibly be associated with hydrothermally altered material from these former volcanic centers (e.g., Boudon et al., 1987). On the other hand, one can notice that the Bouillante hydrothermal area is not characterized by a very low magnetization intensity, possibly because of the low spatial resolution of our inverse model. Nevertheless, this suggests that the Bouillante hydrothermal area is either of a smaller size or characterized by a lower degree of alteration than the hydrothermal system of the Soufrière lava dome.

High magnetizations are, on the other hand, observed near the South-East coast of Basse-Terre both in our model and in sample measurements. These large intensities might be due to the presence of massive lava flows and lava domes constituting the Madeleine vents and the Monts Caraïbes (Boudon et al., 1988).

Medium magnetizations are observed in the South-West of the island in our model as well as in sample measurements, possibly due to the occurrence of less massive material near the surface along the South-East coast. For instance, these moderate values might be partly due to the existence of debris avalanche deposits associated with the collapse of the former Carmichaël volcano, before the Soufrière volcano phase (Boudon et al., 1988, 1989, 2007, 2008) although these deposits are relatively thin (about 50-100 m). Indeed, these debris avalanches are composed of randomly oriented blocks inside a strongly altered matrix and might therefore be characterized by an overall weak magne- 
tization.

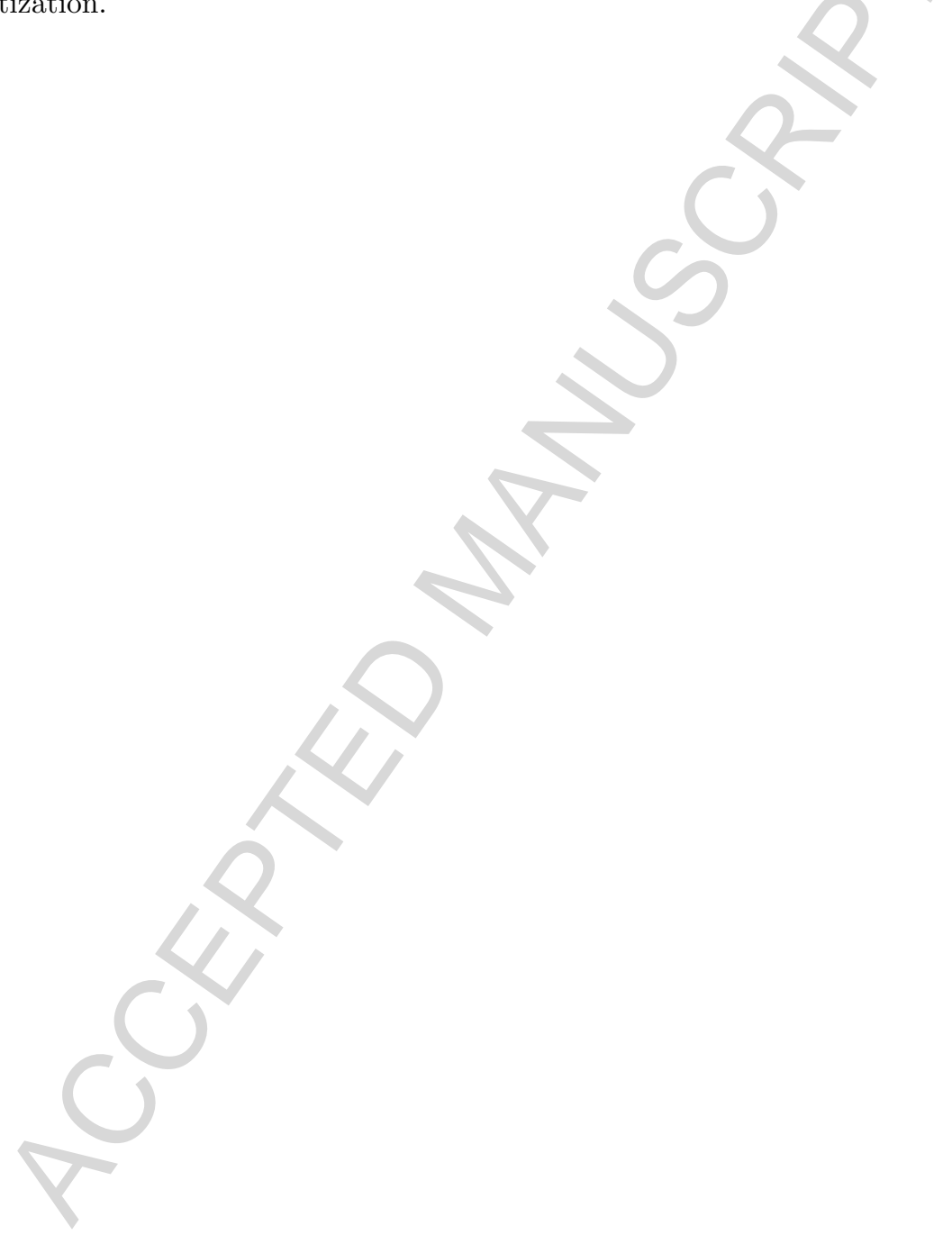




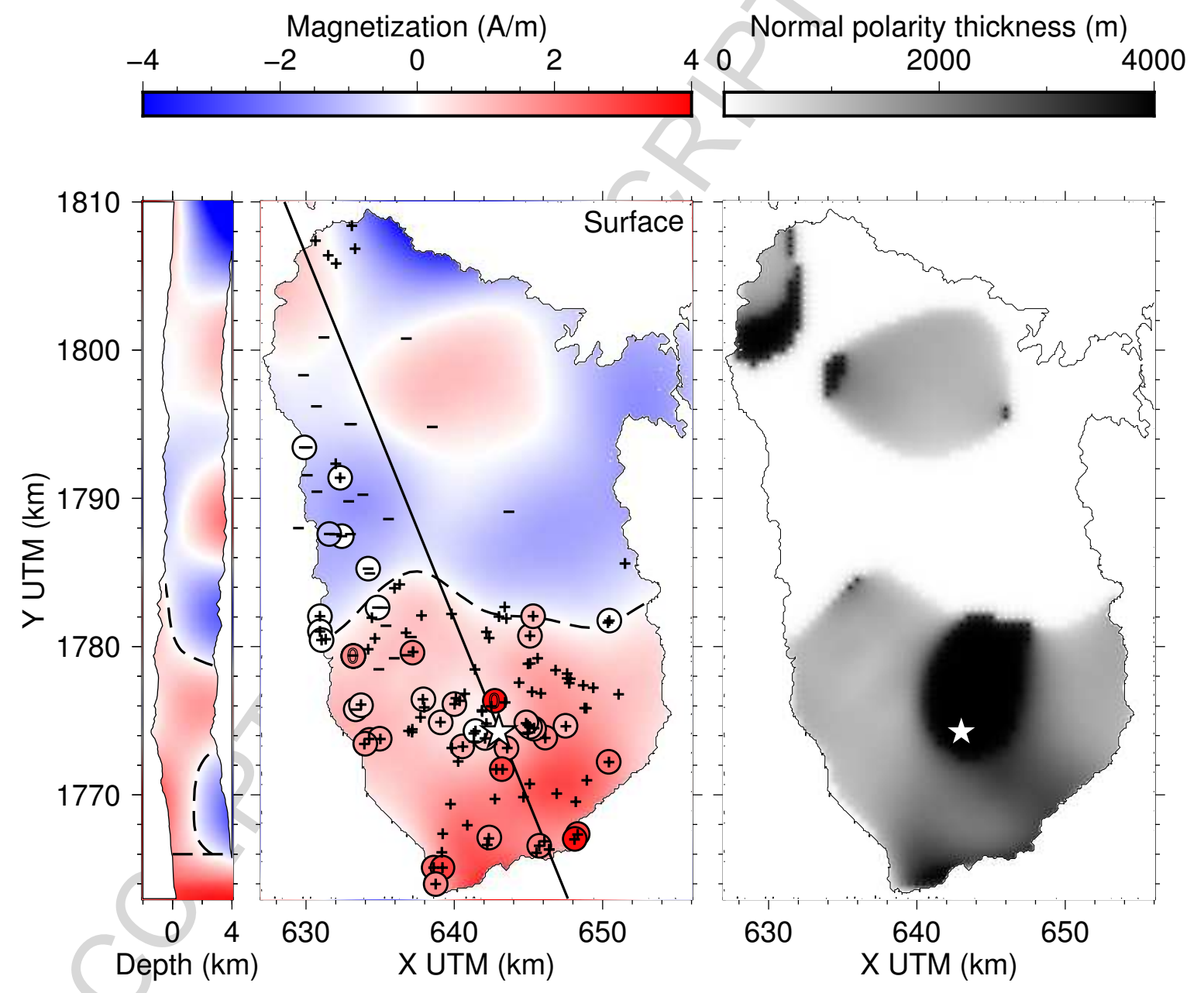

Figure 6: Left: Cross-section of the 3D magnetic model. Center: Comparison of magnetizations measured on rock samples (Carlut et al., 2000; Carlut and Quidelleur, 2000, and Julia Ricci, pers. com.) and polarities deduced from geochronological data (Blanc, 1983; Samper et al., 2007, 2009; Ricci et al., 2015a,b, 2017) with magnetizations extracted from the 3D Bayesian inversion result (fig. 4) by interpolation along the topographic surface. Plus and minus signs indicate normal and reverse polarities deduced from rock sample measurements, zeros indicate transitional directions and filled circles give measured magnetization intensities with the same color scale as the inverted magnetizations. The dotted line delineates, with the coast line, the volume used to estimate the construction rate, up to $4 \mathrm{~km}$ depth below the surface. Right: Thickness of the upper layer of normal polarity below topography. White star: La Soufrière lava dome. 


\subsection{Polarities}

We use the sign of magnetization in our 3D model to infer the polarity of the geomagnetic field recorded in the volcanic substratum. Fig. 6 (right) also displays a map of the thickness of the upper layer of normal polarity to show the vertical extent of some structures. Inverted polarities near the surface (fig. 6, center) are relatively consistent with ages and polarities measured from lava flow samples (Blanc, 1983; Carlut et al., 2000; Carlut and Quidelleur, 2000; Samper et al., 2007, 2009). We recall that this consistency is partly due to the fact that the spatial correlation length was chosen to obtain spatial variations of magnetization at the same length scale as polarities deduced from sample measurements. Small discrepancies are nevertheless observed. The northern limit of the area of normal polarity in the South part of Basse-Terre in our model (dotted line in fig. 6, left and center) does not exactly coincide with the limit deduced from sample measurements (plus and minus signs in fig. 6, center). Our 3D model of magnetization allows identifying structures that are not observed in the available sample measurements. In particular, a shallow region of normal polarity (fig. 6) is inferred in the Septentrional Chain (labelled 2 in fig. 1) in our model while rock samples do not cover this area. This area suggests the occurrence of rock formed during a normal polarity event, possibly at the very beginning of the construction of the Septentrional Chain, that started in the Olduvai normal polarity subchron (1.950-1.770 Myr), or during the Cobb Mountain subchron (1.211-1.201 Myr), short normal interval toward the end of the Septentrional Chain as shown on the geomagnetic time scale of fig. 1. On the other hand, the model does not display an area of normal polarity coinciding with the paleomagnetic samples characterized by a normal polarity in the western part of the Septentrional Chain, suggesting that the volume of this area of normal polarity is too small to be recovered in our model. The normal polarity of the Basal Chain, clearly indicated by sample measurements, is only partly recovered in our model, possibly because of the lack of resolution of the inversion in the very North of the island (see fig. 4b) and of edge effects already mentioned above. Some of these discrepancies between polarities deduced from 
the $3 \mathrm{D}$ model and from samples might be due to the smoothness of our 3D model or to uncertainties in the direction of magnetization (if it deviates from the GAD field). Also, when polarities of rock samples are deduced from the geochronological data only, it should be kept in mind that it is only a statistical inference and that magnetic measurements are mandatory to ensure that the polarity is properly determined especially since lavas could be erupted during short polarity events (as, for instance, the Cobb Mountain event during the Matuyama chron for the $\sim 1.2 \mathrm{Myr}$ old samples from the Septentrional chain, see Samper et al., 2007).

The pattern of polarities significantly differs between the surface and at depth (fig. 4a), attesting to the advantage of using a 3D inversion to enhance subsurface characterization. Isovalues of $0 \mathrm{~A} / \mathrm{m}$ (white color on fig. 4a) correspond to contacts between volcanic units of normal and reverse polarities but do not necessarily correspond to the substratum formed during a polarity reversal as there might be a gap in the volcanic activity between the formation of two volcanic units. The polarities recovered in our model can be used with the geomagnetic time scale to extrapolate ages deduced from sample measurements and give a lower and an upper bound for the age of a volcanic unit. In the following, we attempt to use our 3D model as a tool to delineate edifices at depth. The Axial Chain (see 3 on fig. 1) was partly formed during a period of reverse polarity (0.990-0.780 Myr) and partly during the Brunhes chron (0.780-0 Myr). We observe in our 3D model that the reverse polarity coinciding near the surface with the Axial Chain extends more to the South at depth, suggesting that the early Axial Chain used to extend more to the South, up to the Monts Caraïbes. This is consistent with geological observations suggesting that the Monts Caraïbes and the Grande-Découverte-Carmichaël-Soufrière Complex were built on material from the Axial Chain: lava dated from the Axial Chain period was observed on the southwestern flank of the Grande-Découverte-Soufrière volcano (Samper et al., 2009) and lava blocks with textural and petrological characteristics similar to rocks from the Axial Chain were found in hydromagmatic pyroclastic deposits from the Monts Caraïbes (Georges Boudon, pers. com.). The mate- 
rial formed during the Brunhes chron (i.e., the current normal polarity period) encompasses the latest edifices of the Axial Chain (in particular Pitons de Bouillante area), the Monts Caraïbes, the Icaques-Capesterre and Vieux-Habitants volcanics and the Grande-Découverte-Carmichaël-Soufrière Complex. This normal polarity domain is rather well delineated in our inversion results (fig. 4a and 6) as it overlays a domain of reverse polarity, except below the GrandeDécouverte-Carmichaël-Soufrière Complexe where we can infer the location of the most recent feeding system (see on fig. 6 the area where the thickness of the normal polarity layer reaches $4 \mathrm{~km}$, which is the vertical extent of our model).

We can also use our model to provide an estimate of the volume and averaged rate of construction during the Brunhes period. We assume that the volume of rocks formed during the Brunhes period is delimited by the coastline and the dotted lines marking the polarity change on fig. 6 . The subaerial volume or rocks (i.e. the volume of rocks above sea level) is estimated to $\sim 140 \mathrm{~km}^{3}$, corresponding to an average construction rate of $\sim 1.8 \times 10^{-4} \mathrm{~km}^{3} / \mathrm{yr}$. The total volume, including both subaerial and submarine material (defined here as material within the Basse-Terre island coastline, but lying below sea level), is estimated to $\sim 730 \mathrm{~km}^{3}$, corresponding to an average construction rate of $\sim 9.4 \times 10^{-4} \mathrm{~km}^{3} / \mathrm{yr}$. Note that these estimated rates correspond to long-term average construction rates, encompassing extrusion and erosion that are indistinguishable with such an approach. On the one hand, our estimate considering subaerial material only is generally lower but of the same order of magnitude as construction rates usually obtained for subaerial volumes by previous studies based on geochronological and geomorphological studies: $4.5 \times 10^{-4} \mathrm{~km}^{3} / \mathrm{yr}$ for the Axial Chain (Samper et al., 2007), 5-7 × 10 ${ }^{-4} \mathrm{~km}^{3} / \mathrm{yr}$ for Pitons de Bouillante (Ricci et al., 2015a), 0.9-1.2 × $10^{-4} \mathrm{~km}^{3} / \mathrm{yr}$ for the Monts Caraïbes (Ricci et al., 2015a), $2.4 \times 10^{-4} \mathrm{~km}^{3} / \mathrm{yr}$ as an average over the Axial Chain, the Monts Caraïbes and the Grande-Découverte-Carmichaël-Soufrière Complexe (Lahitte et al., 2012) and $1.8 \times 10^{-4} \mathrm{~km}^{3} / \mathrm{yr}$ for the whole island of Basse-Terre (Lahitte et al., 2012). On the other hand, our estimation of the total volume including submarine material is significantly higher than the values usually found in the 
literature. The main limitation of our approach is that it only provides an order of magnitude as the model of magnetization is smoothed through the constraint of a spatial correlation length. Moreover, we cannot determine a precise error on the volume estimation. However, our approach is more likely to underestimate construction rates because the study area is too small to take into account offshore structures, the method does not take into account the destruction phases which are very important (eg. Boudon et al., 2007; Samper et al., 2007), and it delineates a volume of rock corresponding to a geomagnetic period instead of the geological edifices themselves. Nevertheless, we highlight that the volume of submarine material should not be neglected and that the magnetic structure can be used to bring information about the geometry of volcanic edifices at depth and to bring insight about volcanism dynamics over larger periods of time.

\section{Conclusion}

In this study, we built the first 3D model of magnetization intensity and polarity that accounts for airborne magnetic anomalies over Basse-Terre island. The model was constructed using a grid-node discretization and a Bayesian inversion including an a priori model of magnetization that imposes a correlation length. The a priori model was chosen based on paleomagnetic and geochronological data.

Results of our inversion are consistent with magnetization intensities and polarities deduced from paleomagnetic and geochronological measurements on rock samples. Our model brings new insights on the structure of the island at depth and allows to extend information provided by sample measurements, which are sparsely distributed and restricted to the uppermost meters. The image provided by our model is, however, smoothed and provides only long-wavelength structures. Our model shows that the Soufrière volcano is characterized by almost non-magnetic material, possibly as a result of the intense hydrothermal alteration of the volcanic substratum. High magnetizations are found in the region of the Madeleine vents and Monts Caraïbes, suggesting that these edi- 
fices are composed of very massive lava. Medium magnetizations are observed in the South-West, probably due to less massive lava structures and the presence of debris avalanche deposits associated with the collapse of the Carmichaël volcano. Our model also allows us to delineate the limits of material formed during the Brunhes chron, including material above and below sea level, and to estimate an average construction rate of $\sim 9.4 \times 10^{-4} \mathrm{~km}^{3} / \mathrm{yr}$.

\section{Acknowledgements}

We are grateful to Georges Boudon, Fabio Caratori Tontini and an anonymous reviewer for their comments that greatly helped improve the manuscript. We thank the IPGP for providing us with the aeromagnetic data. The Litto3D data are provided by the Service hydrographique et océanographique de la marine (SHOM) and the Institut national de l'information géographique et forestière (IGN). Financial supports were provided through ANR contracts CATEL/RISK-VOLCAN, RISK-2008/DOMOSCAN and CNRS-INSU PNRN program. Most of the computations presented in this paper were performed using the Froggy platform of the CIMENT infrastructure, which is supported by the Rhône-Alpes region (GRANT CPER07_13 CIRA) and the Equip@Meso project (ANR-10-EQPX-29-01) of the program Investissements d'Avenir supervised by the Agence Nationale pour la Recherche. ISTerre is part of Labex OSUG@2020 (ANR10 LABX56).

\section{References}

Allard, P., Aiuppa, A., Beauducel, F., Gaudin, D., Di Napoli, R., Calabrese, S., Parello, F., Crispi, O., Hammouya, G., Tamburello, G., 2014. Steam and gas emission rate from La Soufrière volcano, Guadeloupe (Lesser Antilles): Implications for the magmatic supply during degassing unrest. Chemical Geology $384,76-93$.

Arnaiz-Rodríguez, M. S., Orihuela, N., 2013. Curie point depth in Venezuela and the Eastern Caribbean. Tectonophysics 590, 38-51. 
Backus, G. E., Gilbert, J. F., 1968. The resolving power of gross Earth data. Geophysical Journal of the Royal Astronomical Society 16, 169-205.

Bansal, A. R., Gabriel, G., Dimri, V. P., Krawczyk, C. M., 2011. Estimation of depth to the bottom of magnetic sources by a modified centroid method for fractal distribution of sources: An application to aeromagnetic data in Germany. Geophysics 76, L11-L22.

Barnoud, A., Coutant, O., Bouligand, C., Gunawan, H., Deroussi, S., 2016. 3-D linear inversion of gravimetric data: method and application to Basse-Terre volcanic island, Guadeloupe, Lesser Antilles. Geophysical Journal International 205 (1), 562-574.

Barthes, V., Mennechet, C., Honegger, J. L., 1984. Prospection géothermique, La région de Bouillante - Vieux Habitants, Guadeloupe : Étude gravimétrique. Technical report, Bureau des Recherches Géologiques et Minières.

Bhattacharyya, B. K., 1964. Magnetic anomalies due to prism-shaped bodies with arbitrary polarization. Geophysics 29, 517-513.

Blakely, R. J., 1995. Potential Theory in Gravity and Magnetic Applications. Cambridge University Press, USA.

Blanc, F., 1983. Corrélations chronologiques et géochimiques des formations volcaniques du sud de la Basse-Terre de Guadeloupe (Petites Antilles), Début du cycle récent. Phd thesis, Université Scientifique et Médicale de Grenoble.

Blanco-Montenegro, I., Nicolosi, I., Pignatelli, A., Garca, A., Chiappini, M., 2011. New evidence about the structure and growth of ocean island volcanoes from aeromagnetic data: The case of Tenerife, Canary Islands. Journal of Geophysical Research: Solid Earth 116 (B3), B03102.

Boichu, M., Villemant, B., Boudon, G., 2011. Degassing at La Soufrière de Guadeloupe volcano (Lesser Antilles) since the last eruptive crisis in 1975-77: 
Result of a shallow magma intrusion? Journal of Volcanology and Geothermal Research 203, 102-112.

Boudon, G., Dagain, J., Semet, M. P., Westercamp, D., 1988. Notice explicative de la carte géologique à $1 / 20000$ e du massif volcanique de la Soufrière. Éditions BRGM, Orléans, France.

Boudon, G., Komorowski, J.-C., Villemant, B., Semet, M. P., 2008. A new scenario for the last magmatic eruption of La Soufrière of Guadeloupe (Lesser Antilles) in 1530 A.D. Evidence from stratigraphy radiocarbon dating and magmatic evolution of erupted products. Journal of Volcanology and Geothermal Research 178, 474-490.

Boudon, G., Le Friant, A., Komorowski, J.-C., Deplus, C., Semet, M. P., 2007. Volcano flank instability in the Lesser Antilles Arc: Diversity of scale, processes, and temporal recurrence. Journal of Geophysical Research: Solid Earth $112, \mathrm{~B} 08205$.

Boudon, G., Semet, M. P., Vincent, P. M., 1987. Magma and hydrothermally driven sector collapses: The 3100 and 11,500 y. B.P. eruptions of La Grande Dcouverte (La Soufrière) Volcano, Guadeloupe, French West Indies. Journal of Volcanology and Geothermal Research 33, 317-323.

Boudon, G., Semet, M. P., Vincent, P. M., 1989. The evolution of la Grande Découverte (la Soufrière) volcano, Guadeloupe (FWI). In: Latter, J. (Ed.), IAVCEI Proceedings in Volcanology, Volcanic Hazards: Assessment and Monitoring. Vol. 1. Springer-Verlag, pp. 86-109.

Bouligand, C., Coutant, O., Glen, J. M. G., 2016. Sub-surface structure of La Soufrière of Guadeloupe lava dome deduced from a ground-based magnetic survey. Journal of Volcanology and Geothermal Research 321, 171-181.

Bouligand, C., Glen, J. M., Blakely, R. J., 2009. Mapping Curie temperature depth in the western United States with a fractal model for crustal magnetization. Journal of Geophysical Research 114, B11104. 
Cande, S. C., Kent, D. V., 1995. Revised calibration of the geomagnetic polarity timescale for the Late Cretaceous and Cenozoic. Journal of Geophysical Research 100, 6093-6095.

Caratori Tontini, F., Ronde, C., Yoerger, D., Kinsey, J., Tivey, M., 2012. 3D focused inversion of near-seafloor magnetic data with application to the Brothers volcano hydrothermal system, Southern Pacific Ocean, New Zealand. Journal of Geophysical Research: Solid Earth 117 (B10).

Carlut, J., Quidelleur, X., 2000. Absolute paleointensities recorded during the Brunhes chron at La Guadeloupe Island. Physics of the Earth and Planetary Interiors 120, 255-269.

Carlut, J., Quidelleur, X., Courtillot, V., Boudon, G., 2000. Paleomagnetic directions and $\mathrm{K} / \mathrm{Ar}$ dating of 0 to 1 Ma lava flows from La Guadeloupe Island (French West Indies): Implications for time-averaged field models. Journal of Geophysical Research 105 (B1), 835-849.

Coron, S., Feuillard, M., Lubart, J. M., 1975. Études gravimétriques en Guadeloupe et dans les îles de son archipel - Petites Antilles. Annales de Géophysique $31,531-548$.

Dentith, M., Mudge, S. T., 2014. Geophysics for the Mineral Exploration Geoscientist. Cambridge University Press.

Dorel, J., Eschenbrenner, S., Feuillard, M., 1979. Coupes sismiques des structures superficielles dans les Petites Antilles - I : Guadeloupe. Pageoph 117, 1050-1063.

Feuillard, M., 1976. Études thermiques à la Soufrière de la Guadeloupe. Bulletin du BRGM IV (4), 375-388.

Feuillet, N., Manighetti, I., Tapponnier, P., Jacques, E., 2002. Arc parallel extension and localization of volcanic complexes in Guadeloupe, Lesser Antilles. Journal of Geophysical Research 107 (B12), 2331. 
Gailler, L., Arcay, D., Münch, P., Martelet, G., Thinon, I., Lebrun, J.-F., 2017. Forearc structure in the Lesser Antilles inferred from depth to the Curie temperature and thermo-mechanical simulations. Tectonophysics 706-707, 7190.

Gailler, L.-S., Martelet, G., Thinon, I., Bouchot, V., Lebrun, J.-F., Munch, P., 2013. Crustal structure of Guadeloupe island and the Lesser Antilles arc from a new gravity and magnetic synthesis. Bulletin de la Société Géologique de France 184 (1-2), 77-97.

Guillen, A., Calcagno, P., Courrioux, G., Joly, A., Ledru, P., 2008. Geological modelling from field data and geological knowledge: Part ii. modelling validation using gravity and magnetic data inversion. Physics of the Earth and Planetary Interiors 171 (1), 158-169.

Gunawan, H., 2005. Gravimétrie et microgravimétrie appliquées à la volcanologie : Exemples de la Soufrière de Guadeloupe et du Mépari. Phd thesis, Institut de Physique du Globe de Paris, Paris, France.

Hirn, A., Michel, B., 1979. Evidence of migration of main shocks during major seismo-volcanic crises of La Soufrière (Guadeloupe, Lesser Antilles) in 1976. Journal of Volcanology and Geothermal Research 6, 295-304.

Honsho, C., Ura, T., Tamaki, K., 2012. The inversion of deep-sea magnetic anomalies using Akaike's Bayesian information criterion. Journal of Geophysical Research 117, B01105.

Hunt, C. P., Moskowitz, B. M., Banerjee, S. K., 1995. Magnetic properties of rocks and minerals. Rock physics \& phase relations: a handbook of physical constants, 189-204.

Komorowski, J.-C., Boudon, G., Semet, M., Beauducel, F., Anténor-Habazac, C., Bazin, S., Hammouya, G., 2005. Volcanic Hazard Atlas of The Lesser Antilles. Ch. Guadeloupe, pp. 65-102. 
Lahitte, P., Samper, A., Quidelleur, X., 2012. DEM-based reconstruction of southern Basse-Terre volcanoes (Guadeloupe archipelago, FWI): Contribution to the Lesser Antilles Arc construction rates and magma production. Geomorphology 136, 148-164.

Le Borgne, E., Le Mouël, J. L., 1976. Le levé aéromagnétique des Antilles françaises, observations magnétiques. Publications IPGP 26.

Le Mouël, J. L., Pozzi, J. P., Rossignol, J.-C., Feuillard, M., 1979. Le levé aéromagnétique de l'archipel de Guadeloupe : description et implications tectoniques. Bulletin de la Société Géologique de France 21 (2), 135-148.

Li, Y., Oldenburg, D. W., 1996. 3-D inversion of magnetic data. Geophysics $61(2), 394-408$.

Manga, M., Hornbach, M. J., Le Friant, A., Ishizuka, O., Stroncik, N., Adachi, T., Aljahdali, M., Boudon, G., Breitkreuz, C., Fraass, A., Fujinawa, A., Hatfield, R., Jutzler, M., Kataoka, K., Lafuerza, S., Maeno, F., Martinez-Colon, M., McCanta, M., Morgan, S., Palmer, M. R., Saito, T., Slagle, A., Stinton, A. J., Subramanyam, K. S. V., Tamura, Y., Talling, P. J., Villemant, B., Wall-Palmer, D., Wang, F., 2012. Heat flow in the Lesser Antilles island arc and adjacent back arc Grenada basin. Geochemistry Geophysics Geosystems $13(8)$, Q08007.

Mathieu, L., van Wyk de Vries, B., Mannessiez, C., Mazzoni, N., Savry, C., Troll, V. R., 2013. The structure and morphology of the Basse Terre Island, Lesser Antilles volcanic arc. Bulletin of Volcanology 75, 700.

Matthieu, F., Pajot, G., Debeglia, N., Jousset, P., Dupont, F. D. L., François, B., 2011. Surveillance gravimétrique du réservoir géothermique de Bouillante (Guadeloupe) - Année 2006-2010. Technical report, Bureau des Recherches Géologiques et Minières.

Maus, S., Gordon, D., Fairhead, D., 1997. Curie-temperature depth estimation 
using a self-similar magnetization model. Geophysical Journal International $129,163-168$.

Okuma, S., Nakatsuka, T., Ishizuka, Y., 2014. Aeromagnetic constraints on the subsurface structure of Usu Volcano, Hokkaido, Japan. Exploration Geophysics 45 (1), $24-36$.

Parker, R. L., Huestis, S. P., 1974. The inversion of magnetic anomalies in the presence of topography. Journal of Geophysical Research 79 (11), 1587-1593.

Parsons, B., Sclater, J. G., 1977. An analysis of the variation of ocean floor bathymetry and heat flow with age. Journal of geophysical research 82 (5), 803-827.

Pilkington, M., Crossley, D., 1986. Determination of crustal interface topography from potential fields. Geophysics 51 (6), 1277-1284.

Portniaguine, O., Zhdanov, M. S., 2002. 3-D magnetic inversion with data compression and image focusing. Geophysics 67 (5), 1532-1541.

Pozzi, J. P., Le Mouël, J. L., Rossignol, J. C., Zlotnicki, J., 1979. Magnetic observations made on La Soufrière volcano (Guadeloupe) during the 19761977 crisis. Journal of Volcanology and Geothermal Research 5, 217-137.

Ricci, J., Lahitte, P., Quidelleur, X., 2015a. Construction and destruction rates of volcanoes within tropical environment: Examples from the Basse-Terre Island (Guadeloupe, Lesser Antilles). Geomorphology 228, 597-607.

Ricci, J., Quidelleur, X., Lahitte, P., 2015b. Volcanic evolution of central BasseTerre Island revisited on the basis of new geochronology and geomorphology data. Bulletin of Volcanology 77 (10), 84.

Ricci, J., Quidelleur, X., Pallares, C., Lahitte, P., 2017. High-resolution K-Ar dating of a complex magmatic system: The example of Basse-Terre Island (French West Indies). Journal of Volcanology and Geothermal Research, in press. 
Salaün, A., Villemant, B., Gérard, M., Komorowski, J.-C., Michel, A., 2011. Hydrothermal alteration in andesitic volcanoes: trace element redistribution in active and ancient hydrothermal systems of Guadeloupe (Lesser Antilles). Journal of Geochemical Exploration 111 (3), 59-83.

Samper, A., Quidelleur, X., Komorowski, J.-C., Lahitte, P., Boudon, G., 2009. Effusive history of the Grande Decouverte Volcanic Complex, southern BasseTerre (Guadeloupe, French West Indies) from new K-Ar Cassignol-Gillot ages. Journal of volcanology and geothermal research 187 (1-2), 117-130.

Samper, A., Quidelleur, X., Lahitte, P., Mollex, D., 2007. Timing of effusive volcanism and collapse events within an oceanic arc island: Basse-Terre, Guadeloupe archipelago (Lesser Antilles Arc). Earth and Planetary Science Letters 258, 175-191.

Spector, A., Grant, F., 1970. Statistical models for interpreting aeromagnetic data. Geophysics 35 (2), 293-302.

Tarantola, A., 2005. Inverse Problem Theory and Methods for Model Parameter Estimation. Society for Industrial and Applied Mathematics, Philadelphia, USA.

Tarantola, A., Valette, B., 1982. Inverse problems = Quest for information. Journal of Geophysics 50, 159-170.

Telford, W. M., Geldart, L. P., Sheriff, R. E., 1990. Applied Geophysics, Second Edition. Cambridge University Press.

Thébault, E., Finlay, C. C., Beggan, C. D., Alken, P., Aubert, J., Barrois, O., Bertrand, F., Bondar, T., Boness, A., Brocco, L., Canet, E., Chambodut, A., Chulliat, A., Coïsson, P., Civet, F., Du, A., Fournier, A., Fratter, I., Gillet, N., Hamilton, B., Hamoudi, M., Hulot, G., Jager, T., Korte, M., Kuang, W., Lalanne, X., Langlais, B., Léger, J.-M., Lesur, V., Lowes, F. J., Macmillan, S., Mandea, M., Manoj, C., Maus, S., Olsen, N., Petrov, V., Ridley, V., Rother, M., Sabaka, T. J., Saturnino, D., Schachtschneider, R., Sirol, O., Tangborn, 
A., Thomson, A., Tøffner-Clausen, L., Vigneron, P., Wardinski, I., Zvereva,

T., 2015. International Geomagnetic Reference Field: the 12th generation.

Earth, Planets and Space 67 (79), 1-19. 


\section{Highlights}

- A 3D model of magnetization is obtained for Basse-Terre island.

- Aeromagnetic data are inverted with a 3D Bayesian linear inversion.

- Our model is consistent with magnetization intensities and polarities of samples.

- Hydrothermal alteration of the Soufrière volcano is imaged by very low magnetization.

- This model helps to constrain volcanic edifices structure and construction rates. 